\title{
Los Irijoles y otras Leguminosas Cultivadas en Chiapas
}

\author{
Por Efraim Hernández Xolocotzi
}

Durante el invierno pasado tuve oportunidad de colectar ochenta y dos muestras de semillas de frijoles y otras leguminosas culti vadas en Chiapas. A pesar de que el estudio completo de estas semillas solamente podrá presentarse después del estudio morfológico y genético que se haga de las mismas, el análisis de estas semillas a través del uso de la magnífica clave presentada por Burkhart en en su obra "Las legumirosas Argentinas Silvestres y Cultivadas", 1943, nos permite hacer las siguientes observaciones preliminares.

De las leguminosas cultivadas, el género Phaseolus es el mejor representado en el Estado, aunque también se cultivan especies de los géneros Vicia, Canavalia, Pachyrhizus, Dolichos, Vigna, Cajanus, y Crotalaria.

Las siguientes especies de Phaseolus se encuentran cultivadas; $P$. vulgaris L., $P$. multiflours Willd. (P. coccineus L.) P. lunatus, $P$. acutifolius Gray. El frijol común( $P$. vulgaris) se cultiva en todas las regiones agrícolas del Estado aurque su mayor producción se localiza en la región escarpada de la altiplanicie de San Cristobal las Casas, Estudios más detallados harán resaltar el gran número de variedades cultivadas en el Estado y denominadas en diferentes regiones por los sigtiientes nombres vulgares; "natalume", "coloradito", "bolita candón", "negro chimbo", "palmero", "ancho o de vara", "tsajal chelnek", "cuarentano", " "enreda", "de veja“, "negro enredo", "gato enreda", "barretón", "blanco", "g a to", "pascua", "torito", "shaquil”, "vaquero" regro de suelo", "negro de bola", "bayo", "temporal tardío", "temporal breve", "isiche colo rado" y "frijol de mata".

El cultivo de P. multiflorus Willd. ("botil" en Chiapas y "ayocote" en la Mesa Central) se limita a las regiones templadas de San

$$
-4-
$$

Hernández-Xolocotzi E. 1947. Los frijoles y otras leguminosas cultivadas en Chiapas. Boletín de la Sociedad Botánica de México 5: 4-6. 
Cristóbal las Casas y Comitán. Cantidades regulares de este frijol llega a los mercados principales del Estado en forma verde y madura para consumo local. La producción del P. acutifolius Gray ("escomites") está limitada a la zona tropical húmeda al sur de la Sierra de Soconusco de Mapastepec a Tapachula. Este frijol se produce en pequeñas cantidades especialmente para consumo local.

El frijol Lima ó $P$. lunatros se cultiva en toda la cuenca supe rior del Río Grijalva. Esta especie se encuentra en un gran número de formas variando entre sí por el color, el tamaño y la forma de las semillas. Algunos de los colores son como sigue: blanco, negro, rojo, blanco con manchas negras, blanco con manchas rojas y rojo con manchas blancas. La mayor parte de las semillas colectadas están fuertemente comprimidas lateralmente aunque dos colecciones tienen una forma globosa característica del tipo "papa" (potato type) de Bailey. Además se encontraron tipos silvestres de esta especie con frecuencia. "Patashete" es el nombre vulgar con el cual se conoce este frijol generalmente, aunque también se le denomina "ishuet" y "huet blanco" en ciertas regiones.

W. Mackie en su artículo sobre Phaseolus lunatus L. (Hilgardía 15 : 1-30,1943) llega a la conclusión de que el centro de origen de esta especie se encuentra en la parte occidental de Guatemala, basándose 'en el gran número de variaciones que se encuentran en esta región y en la existencia de formas silvestres. Pero Mackie no tuvo muestras de este frijol procedentes de la región chiapareca durante sus investigaciones. Ahora, con el material que hemos colectado, podemos concluir en forma preliminar que el centro de origen de esta especie se extiende a la región chiapaneca comprendida en la cuenca superior del Río Grijalva.

El género Vicia está representado por la especie $V$. faba $L$. ("haba") que se cultiva en pequeñas cantidades en la zona templada de las Casas y Cerro Malé. Además en la región del Cerro Malé se cultiva una forma de haba con semillas chicas de color morado, probablemente $V$. faba var. microsperma. La Canavalia ensiforme (L.) D. C. se cultiva en extensiones limitadas cerca de Ocozocoautla y Comitán donde se conoce con los nombres de "frijolón" y "haba blanca". También se encuentran varias especies silvestres de este género en la regiones tropicales del Esstado.

El "chícharo" o "chícharo gandú" Cajanus indicus L., se produce en muy pequeñas cantidades en la parte central de Chiapas. E] 
género Pachyrrhizus, al cual pertenece la jícama de comercio, se encuentra representado por una especie cultivada y por varias especies silvestres. Se encontraron dos especies de Dolichos, el D. Lablab L. con flores y semillas blancas que aparentemente se usa para consumo humano, y una especie con semillas casi totalmente negras y flores moradas que se cultiva para ornamentación.

La colección de semillas de Vigna muestran una variación en color, tamaño y forma. Este género se cultiva especialmente en la parte central del Estado. Pequeñas cantidades de semilla llegan a los mercados de las poblaciones del centro bajo los nombres de "frijol Castilla", "frijol del Perú" y "colón rojo". Finalmente mencionaremos el género Crotalaria del cual se cultiva la especie C. maypurensis $H B K$. ("Chipilín") en las zonas tropicales para la producción de hojas que se consumen localmente en varios guisos regionales. 